\title{
Availability and acceptability of IUDs in Guatemala
}

Carlos Brambila

Berta Taracena

Follow this and additional works at: https://knowledgecommons.popcouncil.org/departments_sbsr-rh

Part of the Demography, Population, and Ecology Commons, International Public Health Commons, Maternal and Child Health Commons, and the Public Health Education and Promotion Commons How does access to this work benefit you? Let us know!

\section{Recommended Citation}

Brambila, Carlos and Berta Taracena. 2003. "Availability and acceptability of IUDs in Guatemala," FRONTIERS Final Report. Washington, DC: Population Council. 


\title{
Availability and Acceptability of IUDs in Guatemala
}

June 2003

\author{
Carlos Brambila \\ Berta Taracena
}

This study was funded by the U.S. AGENCY FOR INTERNATIONAL DEVELOPMENT (USAID) under the terms of Cooperative Agreement number HRN-A-00-98-00012-00 and Population Council In-house Project number 800213056 426. The opinions expressed herein are those of the authors and do not necessarily reflect the views of USAID. 


\section{Table of Contents}

\section{List of}

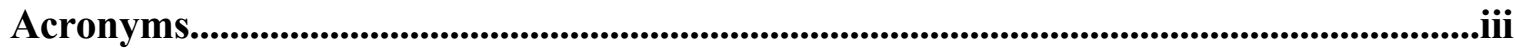

SUMMARY

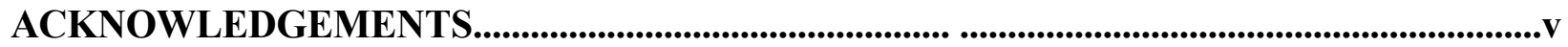

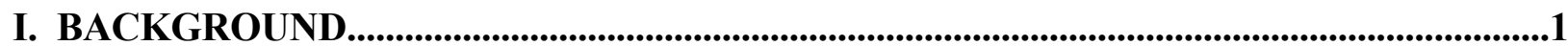

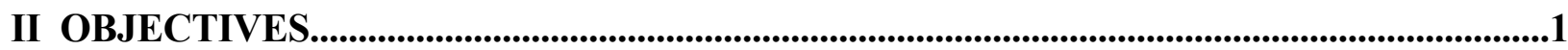

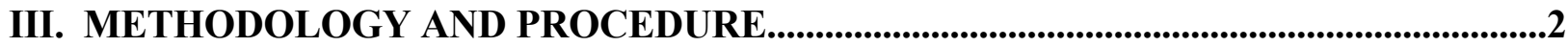

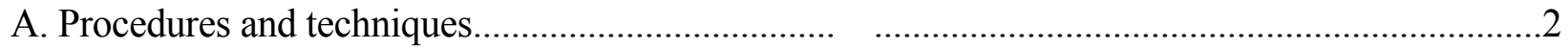

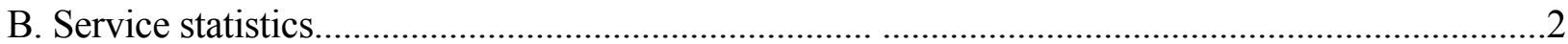

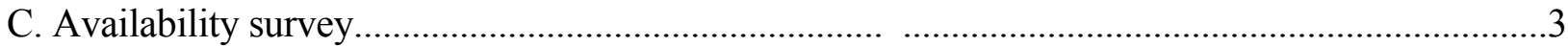

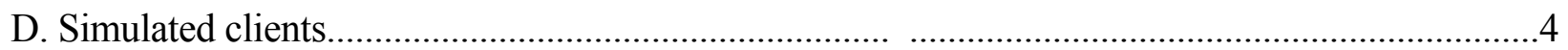

E. In-depth interviews with service providers......

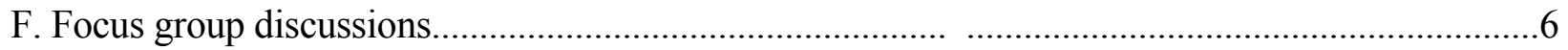

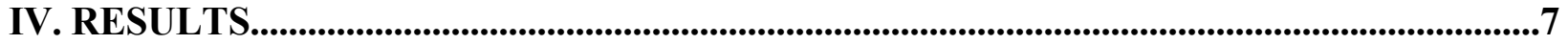

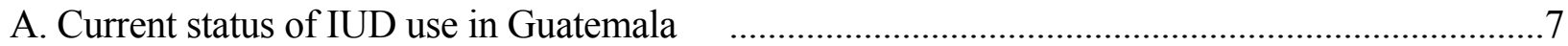

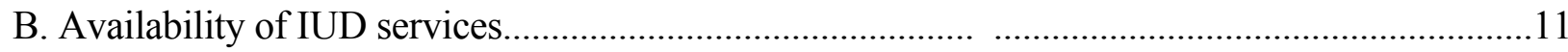

C. Acceptability of IUDs as a contraceptive choice. .16

V. CONCLUSIONS.......................................................................................................................................23

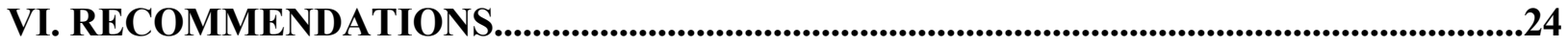

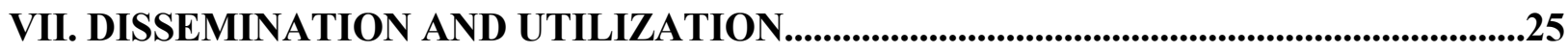

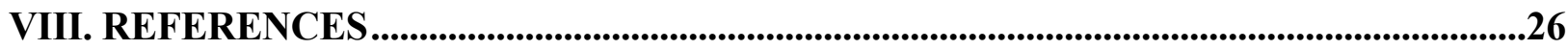




\section{List of Acronyms}

\begin{tabular}{|c|c|}
\hline APROFAM & $\begin{array}{l}\text { Asociación Pro Bienestar de la Familia (Pro-Family Wellbeing } \\
\text { Association) }\end{array}$ \\
\hline ENSMI & $\begin{array}{l}\text { Encuesta Nacional de Salud Materno Infantil (Maternal and Child Health } \\
\text { Survey) }\end{array}$ \\
\hline FGD & Focus Group Discussion \\
\hline IEC & Information Education and Communication \\
\hline IGSS & $\begin{array}{l}\text { Instituto Guatemalteco de Seguridad Social (Guatemalan Institute of } \\
\text { Social Security) }\end{array}$ \\
\hline IUD & Intrauterine device \\
\hline JSI & John Snow International \\
\hline MSPAS & $\begin{array}{l}\text { Ministerio de Salud Pública y Asistencia Social (Ministry of Public } \\
\text { Health and Social Assistance) }\end{array}$ \\
\hline NGO & Non-governmental organization \\
\hline $\mathrm{SAC}$ & Sistema Administrativo de Clínicas (Clinic Management System) \\
\hline SIGSA & Sistema Gerencial de Salud (Managerial Information System) \\
\hline SPSS & Statistical Package for the Social Sciences \\
\hline USAID & U.S. Agency for International Development \\
\hline
\end{tabular}




\section{SUMMARY}

The purpose of this study was to identify the reasons for the low use of the IUD in Guatemala and to explore the reasons why other reversible methods are selected more frequently than IUDs. The study aimed to determine the availability and acceptability of IUDs as a contraceptive option within the Ministry of Health (MSPAS), the Guatemalan Social Security Institute (IGSS), and APROFAM.

The study used a combination of quantitative and qualitative techniques to measure different aspects of the supply and demand for IUD services. Qualitative techniques used included: a simulated (mystery) client study, in-depth interviews with service providers, and focus group discussions with actual and potential clients.

The institutional statistics point toward a lack of contraceptive options available to women, having to choose among only two or three methods. Results of the availability study at MSPAS Health Districts show that 30 percent of the surveyed clinics offer IUD services. Among these, more than half $(62.8 \%)$ have a monthly average of one or two IUD insertions, while only 11.6 percent of clinics insert an average of five or more IUDs per month. The low coverage of IUD services is despite the fact that 90.8 percent of clinics have the necessary infrastructure, 48.2 percent have the basic equipment needed, 53.9 percent have at least one IUD in stock, and 89.4 percent have at least one trained professional able to provide IUD services.

Results from this study show that for young simulated clients wanting to space their pregnancies, 40.8 percent of providers offered at least one item of information about the IUD as a family planning method. A total of 59.2 percent of providers did not mention IUDs to birth-spacing clients at all. Results obtained by simulated clients with a limiting profile were very similar, indicating that service providers do not take into consideration women's reproductive needs or intentions when they provide family planning counseling.

In-depth interviews indicate that health care providers are only partially trained to offer IUD services. Providers still lack information about IUDs and are misinformed about the side effects and contraindications of this method. Almost half of the providers who perceive a low use of the IUD blame demand factors for it, although close to a third recognize that supply factors are also responsible.

This study shows that there are several demand-side factors that affect the use of the IUD, including lack of knowledge about the method, lack of accessibility, fears, perceived disadvantages and low quality of services. The main source of fear about the IUD results from the lack of information offered by service providers. Often times, service providers perpetuate myths and fears about the method. Programmatic recommendations are drawn accordingly. 


\section{ACKNOWLEDGEMENTS}

This project was a truly collaborative effort among institutions active in the reproductive health field in Guatemala. The study was designed by Elizabeth Eggleston, Carlos Brambila and Ricardo Vernon. The principal investigator was Dr. Berta Taracena who worked in close collaboration with Dr. Jorge Solorzano. The availability study was conducted thanks to collaboration and support from representatives and officers of the major service provision institutions. Dr. Julio Garcia Colindres, Director of the National Reproductive Health Program, and the Health Area Directors of MSPAS granted access to FRONTIERS staff to collect and verify information at MSPAS health centers and posts. Dr. Gustavo Gutierrez, Officer of the Reproductive Health Program of IGSS, provided support to conduct the study at IGSS hospitals and clinics. Dr. Thelma Duarte helped in the design of the study and provided access to APROFAM's clinics and staff.

Each service provision institution and the Calidad en Salud program, including Drs. Edwin Montufar and Werner Figueroa, provided service statistics. The qualitative analysis was originally designed by Elizabeth Eggleston and implemented by Estudio 1360, a consultancy directed by Dr. Linda Asturias. Focus group discussions and in-depth interviews were conducted in collaboration with the NGOs Renacimiento and Belejeb' Batz, long-term Council partners and collaborators.

Training and field work using simulated clients was conducted under supervision of Rosa Monge, consultant based in Peru, and implemented by Dr. Marisela de la Cruz. Martha Silva, doctoral student at Tulane University, collaborated in the development of this report.

The data collection instruments used in this study are available in Spanish only and may be requested from the investigators. 


\section{BACKGROUND}

According to the National Maternal and Child Health Survey (Encuesta Nacional de Salud Materno Infantil, ENSMI, 1999), the prevalence of contraceptive use among married women and women in union in Guatemala is 38.2 percent, of which 30.9 percent are users of modern methods and 7.2 percent are users of traditional methods and periodic abstinence. Among the modern methods, the most popular are female sterilization (16.7\%), the pill $(5.0 \%)$, the injection $(3.9 \%)$ and the condom (2.3\%). Only 2.2 percent of women in union use IUDs, a smaller proportion than those that used this method in 1995 (2.8\%), which is indicative of its lack of supply as well as the lack of demand for this method in the health service system.

IUD use in Guatemala may be considered low with respect to the estimated demand for long-term methods. ENSMI estimates that 23.1 percent of women in union have an unmet need for family planning services, of which nearly half $(11.3 \%)$ have an unmet need for sterilization or other longterm methods. The negative consequence of this situation is that many women opt for sterilization, or fail to adopt a method, while in fact they would prefer to use a long-term temporary method.

It is not clear what the causes are for the low use of the IUD in Guatemala: it is possible that the method has a bad reputation, that adequate information is not given or that the quality of the service is poor. To offer a more balanced range of contraceptive options in the country, it is necessary to determine the reasons for low method use.

\section{OBJECTIVES}

The purpose of this study was to identify the reasons for the low use of the IUD in Guatemala and to explore the reasons why other reversible methods are selected more frequently than IUDs. The study aimed to determine the availability of IUD services and the acceptability of IUDs as a contraceptive option within the Ministry of Health (MSPAS), the Guatemalan Social Security Institute (IGSS), and APROFAM.

The main project objectives were: (1) to determine the national coverage and availability of IUD services provided by the MSPAS, IGSS and APROFAM, (2) to assess providers' attitudes regarding the IUD and if these attitudes influence whether IUDs are offered and/or recommended to clients who request family planning services, and (3) to explore family planning client knowledge, source of knowledge, experience and attitudes about IUDs, and client knowledge of where and how to obtain the method.

This study aims to study availability and acceptability factors affecting the low use of IUDs in Guatemala. Availability includes the following four aspects or components: (1) the availability of the IUD, (2) the availability of equipment, including IUD insertion kits and gloves, (3) the availability of infrastructure, which refers to a clean, private room where the insertion can be done and (4) the availability of trained service providers. Acceptability of the method involves both service providers and clients. On the provider side, past experience with the method and attitudes toward it will affect their willingness to provide it. If a provider does not promote a method, or if the user of a method is not well informed by the provider, the method is unlikely to be widely 
accepted. On the consumer side, acceptability may be influenced by beliefs, attitudes, knowledge, and previous experience with the method.

This study is relevant for USAID/Guatemala's Intermediate Objective to achieve "increased use of quality reproductive health services," and provides important information to design strategies relevant to FRONTIERS's IR1, "design of innovative solutions." Information provided by this study will help service provision institutions in Guatemala to take steps to provide comprehensive family planning counseling, including about the IUD as a contraceptive alternative. More comprehensive family planning counseling services are expected to generate an increased demand for IUDs within the National Family Planning Program.

\section{METHODOLOGY AND PROCEDURE}

\section{A. Procedures and techniques}

To analyze supply and demand factors, this study used a combination of quantitative and qualitative techniques to measure different aspects of IUD services, as follows:

1. To review existing studies and surveys, the investigators conducted a literature review and interviews with researchers and program managers.

2. To determine the national coverage and availability of IUD services, the investigators analyzed and evaluated the quality of available statistical information and conducted a nationwide survey on the availability of supplies and infrastructure available by using a random sample of medical units of the three main service providers: MSPAS, IGSS and APROFAM.

3. To assess providers' attitudes, the study conducted 87 in-depth interviews among service providers.

4. To explore contraceptive method user knowledge, the study conducted 30 focus groups among three different types of users.

5. To assess the quantity, content and accuracy of IUD counseling provided to family planning clients, the study conducted 76 simulated client visits using two user profiles (limiting and spacing users).

The following sections describe how each of the above procedures was implemented.

\section{B. Service statistics}

In a collaborative effort with the Calidad en Salud project, FRONTIERS compiled information on IUD services available at the MSPAS, IGSS, and APROFAM. The data was analyzed and evaluated for consistency and reliability.

Three main sources for MSPAS data are:

1. Consumption data, comparing contraceptive inventory at the beginning of each month to that at the end of the month. 
2. SIGSA (Sistema Gerencial de Salud), the national MSPAS centralized management information system that collects data from each center about new family planning clients and the type of method chosen.

3. Hospital data, primarily for female and male sterilization. This data is collected directly from hospitals because it is infrequently reported to the Health Area offices.

The quality of the data collected from these three sources varies. Hospital data concerning surgical methods are considered the most reliable, as surgery room records remain at the hospital. Consumption data are also considered reliable as they are collected by inventory, although information based on inventory may potentially over-estimate the number of contraceptive users. SIGSA data are considered the most unreliable and therefore only information about new users is taken into account. The Calidad en Salud project takes into consideration these three sources as well as their varying levels of reliability in order to consolidate MSPAS information into one official record.

APROFAM data were requested directly from the organization, and is considered reliable. Their clinic statistics are compiled monthly through a computerized information system called Sistema Administrativo de Clínicas-SAC (Clinical Administrative System).

\section{Availability survey}

The IUD service availability study included MSPAS, IGSS and APROFAM clinics nationwide. The study aimed to collect institutional information on the availability of IUD services at each of the medical units that potentially may offer this service. Availability of IUD services includes the four elements mentioned in a previous section (Concepts and Definitions): (1) the availability of IUDs, (2) the availability of equipment (i.e. IUD insertion kits and gloves), (3) the availability of infrastructure (i.e. clean, private room where the insertion can be made), and (4) the availability of trained service providers. A questionnaire consisting of seven sections was designed and administered to representatives of each health unit.

A random sample of 142 centers was drawn from the total of 281 MSPAS centers in the country. This sample was then divided into four regions: Central, Western Highland, Eastern and Northern regions. Information for one health center could not be gathered, since the person responsible for that center was not available both times the field worker arrived. Thus, the response rate was 99.3 percent, leaving the final sample size at 141 health centers. Similarly, random samples of APROFAM and IGSS clinics were drawn from complete national listings. A sample of nine out of 26 APROFAM clinics was chosen and seven out of 16 clinics were chosen for IGSS.

A team of four health professionals was formed and trained to administer the survey, all with previous experience in survey data collection and knowledge about MSPAS services. Subsequently each team member was assigned a region of the country to collect data from, closely supervised by the study coordinator. Data collection was carried out during a three-week period between April and May of 2002. A noteworthy aspect of this study was the close collaboration between the 
MSPAS and FFRONTIERS. Each health area was responsible for providing transportation, as well as notifying the health center attendants of their visits. Once the interviewer arrived at each service delivery outlet, the attendant in charge was identified and asked to provide information as described in the previous section. In addition, interviewers were asked to verify information (i.e. counting the number of IUDs in stock) and assess the state of their equipment. Quality control procedures included supervised data collection visits and re-visits to selected sites for data confirmation.

In order to measure each of the four aspects of IUD service availability mentioned in the objectives, four different indices were constructed. The first index was constructed to assess the level of availability of IUDs in each center. This scale was constructed using the number of units in stock that had not expired. In order to organize this information, this index was grouped in three categories: places that did not have IUDs, those that had from one to five units in stock, and those that had more than six units in stock. To assess the existence of equipment, two separate indices were constructed. The basic equipment index consisted of three items deemed absolutely essential to insert IUDs: a speculum, uterine sound, and a uterine clamp. A second index for full equipment consisted of all seven items needed to adequately offer IUD insertion services. In addition to the three items included in the basic equipment index, the full equipment index was comprised of an autoclave, scissors, disposable gloves, and antiseptic solution. An infrastructure index was constructed using the three items of infrastructure deemed most important in offering IUD services. These three items were: a private space to conduct a gynecological exam, a gynecological bed, and electricity. Lastly, the fourth index measured the number of qualified personnel within each center.

\section{Simulated clients}

The simulated client, or "mystery client," study aimed to investigate the quality (including the quantity, content and accuracy) of IUD counseling provided to family planning clients. The Service Test (see León, 1999; León et al., 2001) is a methodology that uses simulated clients and produces objective behavioral measurements of providers during the delivery of services. It consists of a series of stimuli, in which a certain "correct" answer is expected on the part of the provider. Two simulated clients were pre-selected and trained by an international consultant with experience in the Service Test. The final selection of simulated clients depended on their performance in a data collection role-playing that included the completion of the observation checklist. Each team consisted of a supervisor and two simulated clients, each corresponding to a different user profile. The details of these profiles are explained below.

Before visits from the simulated client took place, the facilities were visited by the team supervisor who obtained informed consent from providers agreeing to participate in the study. They also obtained the statistics on family planning services and all other services in the establishment for the previous three months. A total of 76 MSPAS Health Centers and Health Posts in four Health Areas of the Eastern and Western Highlands regions were visited by simulated clients of both profiles between the months of October and December of 2001.

As previously mentioned, two user profiles were developed. The first profile described a young woman that wanted to have more children in the future, and who had previous experience with oral 
contraceptives but did not want to use them again. This profile is referred to as the birth-spacing client. The second profile was of an older woman who did not want to have any more children, referred to as the birth-limiting profile. Although the client of the first profile chose to use DepoProvera, and the woman of the second profile requested sterilization, both profiles were adequate to be considered IUD candidates as well.

Six items of the observation checklist were used to assess whether IUDs were presented to clients as a contraceptive option, as well as the quantity and quality of information provided. These six items were: whether the IUD was described and information was given about how it is inserted; the time-span over which it protects against pregnancy; and its side effects, contraindications and risk factors. Indices were also formed to assess if birth-spacing clients received information about other methods, such as Depo-Provera (four items), oral contraceptives (four items), and condoms (four items). The index to assess if birth-limiting clients received information about other long-term methods included four items on Depo-Provera, six items on female sterilization, and five items on male sterilization.

\section{E. In-depth interviews with service providers}

The objective of in-depth interviews was to assess providers' attitudes regarding IUDs and if these attitudes influence whether IUDs are offered and/or recommended to clients who request family planning services; and to assess the quality (including the quantity, content and accuracy) of IUD counseling provided to family planning clients.

A total of 87 semi-structured interviews were carried out between February and March of 2002 in three regions of the country: Central, Western Highland and Eastern Guatemala. Approximately 30 interviews were carried out in each region in 15 MSPAS, IGSS, APROFAM and NGO health centers and clinics. Once the regions were defined, the health centers and clinics were randomly chosen from complete regional listings. Field work included the development of a semi-structured interview guide, training of field workers, data collection and supervision, and data input and analysis.

Semi-structured interviews were carried out with physicians in charge of the clinic or center that provided family planning services, as well as with professional nurses or nurse auxiliaries in charge of the family planning program. A total of two providers per clinic or center were interviewed. Written authorization was requested in advance from program directors of each institution, and informed consent was obtained from providers to be interviewed. Interviews had a maximum duration of 45 minutes.

A guide was developed to conduct the semi-structured interviews which consisted of six sections: demographic information; information on previous training to provide IUD services; knowledge about side effects, contraindications, advantages and disadvantages of the method; attitudes regarding the IUD as a method; quality of IUD services; and suggestions to improve the services. The guide was developed and validated by an interdisciplinary group of professionals from FRONTIERS and Estudio 1360, a Guatemalan research consulting group. 
Six field workers were trained to conduct the interviews, forming three teams of two interviewers each to allow for one team in each region of the country covered by this study. One member of each team was a physician, in charge of interviewing physicians as well as supervising the team, while the other member was an anthropologist or social worker in charge of interviewing nurses or nurse auxiliaries.

In order to analyze the information collected by providers, indices were created to measure knowledge and misinformation, as well as providers' attitudes towards the IUD and supply practices. Differences between regions, institutions, and type of providers were assessed.

\section{F. Focus groups}

The objective of this study was to explore family planning client knowledge, source of knowledge, experience and attitudes about IUDs, and client knowledge of where and how to obtain the method.

A total of ten focus group discussions (FGDs) were conducted in each of the three selected regions (Guatemala City, Highlands and South-West), for a total of 30 FGDs. In each region, FGDs were conducted with women who wish to space children (spacers), with women who wish to limit children (limiters), and with current or past IUD users. Focus group participants were recruited from different sites, including family planning clinics and maternal-child health centers, and through announcements in other public places. Focus group discussions were conducted with a maximum of 12 and a minimum of three women in each. The FGDs were held in both rural and urban settings. Group informed consent was obtained verbally prior to conducting the discussions. To the extent possible, monolingual women were encouraged to participate in FGDs, and their statements were translated by volunteer collaborators and other women participating in the discussions.

A total of 10 focus groups were held with current users of re-supply methods. These women were considered spacers. To be eligible to participate in these focus groups, women needed to: (a) receive their method within the past four months, and (b) be between 17 and 40 years of age.

Ten focus groups were conducted with sterilized women. These women were considered limiters. Two focus groups were conducted in urban areas and two in rural areas. Eligibility criteria were: (a) sterilized in the past 10 years, and (b) between 25 and 50 years of age.

Ten groups were held with current or past users of IUDs. Both groups were conducted in a metropolitan area since this is where most Guatemalan women who have used the IUD reside. Women from rural areas were not included due to the fact that IUD use is very low in these areas. To be eligible to participate in focus groups, women were required to be: (a) current users of IUDs or users within the last five years, and (b) between 17 and 40 years of age.

Field work included the development of three focus group guides, the training of moderators and observers, the transcriptions of focus group discussions, and the development of a code tree and text coding. A group of seven moderators and observers were selected and trained to carry out the field work. All team members had previous experience with focus group research. The team was 
trained to perform the following tasks: verify the profile of FGD participants, follow FGD guides, moderate and observe FGDs, record information through tape recording and observer notes, and transcribe FGD recordings. In addition, training included a module on contraceptive methods to ensure adequate background knowledge of the research topic.

In order to analyze the FGD information a hierarchy of codes was developed to classify information using the program Winmax Pro. Thirty focus group discussions were transcribed using a code tree of four different levels. One investigator coded all transcriptions, and two other investigators checked these codes for inter-coder reliability. Under the topic of knowledge, codes such as "knowledge," "lack of knowledge," and "misinformation" were used. "Knowledge" refers to biomedical knowledge about the method. "Lack of knowledge" is defined as the absence of knowledge. "Misinformation" was defined as wrong or incongruent information from the biomedical perspective.

An analysis plan was developed according to the objectives of this investigation, and matrices were used to allow for more interpretable results and comparisons between analytical categories, type of woman and region.

\section{RESULTS}

\section{A. Current status of IUD use in Guatemala: Service statistics}

\section{$\underline{\text { Ministry of Health }}$}

Figure 1 shows the method mix among new users ${ }^{1}$ for 2001 among women who sought family planning services in MSPAS clinics and Health Posts. Service statistics show that 80 percent of all family planning recipients used one of two methods: Depo-Provera $(67 \%)$ or oral contraceptives (12.9\%). The third most commonly used method was the condom with 9.6 percent of users in 2001. Only 6.5 percent were users of female sterilization and 3.1 percent were users of the IUD, the least commonly used method among women.

\footnotetext{
${ }^{1}$ New users were calculated on the basis of methods distributed and consumption of supplies. CYP conversion factors are used to translate pills, condoms and injectables distributed into an estimated number of new users. IUD, Norplant and VSC new users were estimated directly from the number of users reported by institutional statistics. Following the most recent CYP conversion factors available (Contraceptive Technology, 2001), this study used the following: Depo-Provera, four doses per user per year; Condom, 120 units per user per year; Oral, 15 cycles per user per year.
} 
Figure 1. New users MSPAS: 2001

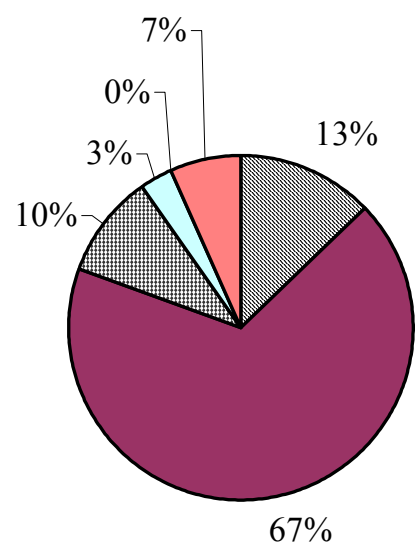

\begin{tabular}{|l|}
\hline Oral \\
$\square$ Depo-provera \\
$\square$ Condom \\
$\square$ IUD \\
$\square$ Vasectomy \\
$\square$ Tubal ligation \\
\hline
\end{tabular}

Throughout the country, a total of 3,573 IUDs were inserted by MSPAS hospitals and clinics during 2001, averaging almost 298 IUD insertions a month. According to the service statistics, more than half (54\%) of all IUD insertions are conducted in three departments: Guatemala, Alta Verapaz, and Santa Rosa. Furthermore, of all 26 departments in Guatemala, eleven of them had an average of less than five IUD insertions per month. Service statistics for MSPAS clinics and health centers illustrate the extent to which IUD use is concentrated in few places, and is mostly underused throughout the country.

\section{$\underline{\text { IGSS and APROFAM }}$}

Service statistics for IGSS and APROFAM reflect similar patterns. Figure 2 (below) shows the method mix among women seeking services in all IGSS locations during 2001. Forty-one percent of family planning new users used Depo-Provera, 17 percent used condoms, 16 percent used tubal ligation, 11 percent used oral contraceptives, and 8 percent used Norplant. Only 6.2 percent of new users preferred IUDs. 
Figure 2. New users IGSS: 2001

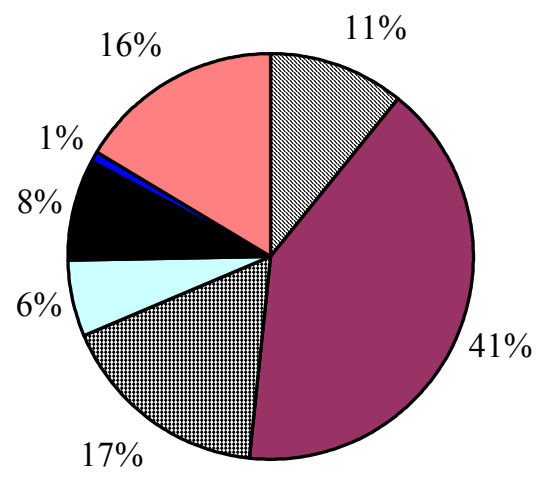

\begin{tabular}{|l|}
\hline Oral \\
$\square$ Depo-provera \\
⿴囗Condom \\
$\square$ IUD \\
Norplant \\
$\square$ Vasectomy \\
$\square$ Tubal ligation \\
\hline
\end{tabular}

According to ENSMI 1999, the IGSS is the second most important IUD service provider after APROFAM. Service statistics shown in Table 1 indicate that in 2001, IGSS hospitals and clinics inserted a total of 1,965 IUDs, 90.6 percent of which where inserted in three locations in Guatemala City.

\begin{tabular}{|l|c|c|}
\hline Table 1. IGSS IUD insertion statistics for $\mathbf{2 0 0 1}$ \\
\hline \multicolumn{1}{|c|}{ Location } & IUDs inserted & Percent \\
\hline OB/GYN Hospital (Guatemala) & 1452 & 73.9 \\
\hline Juan José Arévalo Hospital (Guatemala) & 221 & 85.1 \\
\hline Clínica periférica zona 5 (Guatemala) & 108 & 90.6 \\
\hline Other IGSS locations & 184 & 100.0 \\
\hline Total & 1965 & \\
\hline
\end{tabular}

Source: Service Statistics - IGSS Guatemala, 2001

The method mix coming from APROFAM services during 2001 is similarly dominated by DepoProvera. An estimated 38.8 percent of new APROFAM users preferred Depo-Provera, 17.4 percent used tubal ligation, 14.7 percent used IUDs, and 12.2 percent used oral contraceptives.

APROFAM's clients also prefer other hormonal methods such as Cyclofem (5.7\%) and Noristerat $(5.7 \%)$. Three percent of new users opt for Norplant and 2 percent for male sterilization. 
Figure 3. New users APROFAM: 2001

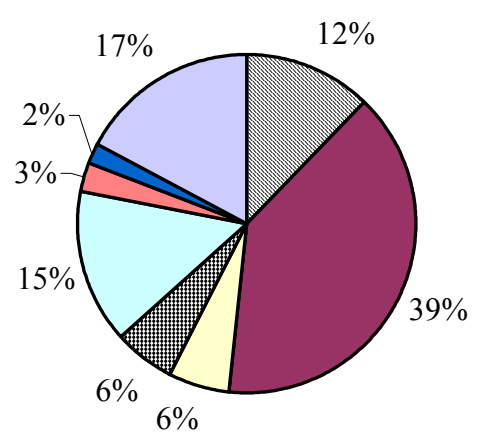

\begin{tabular}{|l|}
\hline Oral \\
$\square$ Depo-provera \\
$\square$ Cyclofem \\
$\square$ Condom \\
$\square$ IUD \\
$\square$ Norplant \\
$\square$ Vasectomy \\
$\square$ Tubal ligation \\
\hline
\end{tabular}

Comparing the method mix for MSPAS, IGSS, and APROFAM, as shown in Table 2, the country's three largest family planning service providers offer a method mix dominated primarily by Depo-Provera. Only at APROFAM does the IUD constitute an important method.

\begin{tabular}{|l|c|c|c|}
\hline \multicolumn{4}{|c|}{ Table 2. New users 2001 in percentages by institution } \\
\hline & APROFAM & IGSS & MSPAS \\
\hline Oral & 12.2 & 10.9 & 12.9 \\
\hline Depo-provera & 38.8 & 40.7 & 67.8 \\
\hline Noristerat & 0.2 & 0.0 & 0.0 \\
\hline Cyclofem & 5.7 & 0.0 & 0.0 \\
\hline Condom & 5.7 & 17.1 & 9.6 \\
\hline Foaming tablet & 0.4 & 0.0 & 0.0 \\
\hline IUD & 14.7 & 6.2 & 3.1 \\
\hline Norplant & 2.7 & 8.0 & 0.0 \\
\hline Vasectomy & 2.0 & 1.0 & 0.1 \\
\hline Tubal ligation & 17.4 & 16.3 & 6.5 \\
\hline Total & 100.0 & 100.0 & 100.0 \\
\hline New users 2001 & $\mathbf{3 7 , 9 9 6}$ & $\mathbf{3 1 , 8 2 0}$ & $\mathbf{1 1 6 , 0 5 6}$ \\
\hline
\end{tabular}

Source: MSPAS, IGSS, and APROFAM Service Statistics - Guatemala, 2001

The statistics point towards a lack of contraceptive options available to women, having to choose among two or three methods. Having a few methods driving the contraceptive market can be considered a shortcoming, given the diversity of women's reproductive needs and intentions. Secondly, the institutional capacities, particularly for MSPAS and IGSS, are largely wasted. Many clinics and health centers that have the technical capacity to offer IUD services as well as other contraceptive methods are currently not offering them. 


\section{B. Availability of IUD services}

\section{Health centers and IGSS clinics: Availability survey}

\section{Ministry of Health}

The availability survey sample included a total of 141 health centers in four different regions of the country, and comprised approximately 50 percent of the total number of MSPAS district level health centers. Forty-one sampled clinics were located in the Central region of the country, 54 clinics were from the Western Highland region, 27 clinics from the Eastern region, and 19 from the Northern region.

Table 3 summarizes the IUD availability data for MSPAS health centers. Results show that 30 percent of surveyed clinics offer IUD services. Among these, more than half $(62.8 \%)$ have a monthly average of one or two IUD insertions, while only 11.6 percent of clinics insert on average five or more IUDs per month. Among the centers that offer IUD services, a great majority (72.1\%) are able to provide the service at any time during normal business hours, and have an open and accessible schedule. In terms of IEC materials, 75.2 percent of all surveyed clinics have on the premises at least one type of written material containing information about IUDs, 80.9 percent have at least one type of visual aid to explain the service to potential clients, and 82.3 percent include IUD information in their family planning lectures.

The low coverage of IUD services is despite the fact that 90.8 percent have the necessary infrastructure, 48.2 percent have the basic equipment needed, 53.9 percent have at least one IUD on site, and 89.4 percent have at least one trained professional to insert IUDs.

Table 3. Availability of IUD services in MSPAS centers
\begin{tabular}{|l|c|c|}
\hline & Percent & $\mathrm{N}$ \\
\hline Percentage of health centers that provide IUD service (1+) & 30.5 & 141 \\
\hline Monthly average of 1-2 IUD insertions & 62.8 & 43 \\
\hline Monthly average of 3-4 IUD insertions & 25.6 & 43 \\
\hline Monthly average of 5 or more & 11.6 & 43 \\
\hline Percentage of health centers that have: & & \\
\hline Basic infrastructure & 90.8 & 141 \\
\hline Basic equipment & 48.2 & 141 \\
\hline Full equipment & 34.8 & 141 \\
\hline IUD in stock & 53.9 & 141 \\
\hline At least one trained staff member & 89.4 & 141 \\
\hline $\begin{array}{l}\text { Minimum availability conditions (including 4 } \\
\text { availability elements) }\end{array}$ & 34.8 & 141 \\
\hline All availability conditions & 21.3 & 141 \\
\hline
\end{tabular}

Source: IUD Availability Survey - FRONTIERS Guatemala, 2002 
Basic infrastructure refers to the existence of a private area to conduct an exam, a gynecological bed and electricity. Basic equipment refers to the existence of a speculum, uterine sound, and uterine clamp. Full equipment refers to the existence of a speculum, uterine sound, uterine clamp, autoclave, speculum, scissors, disposable gloves, and antiseptic solution. IUD supply refers to at least one IUD unit on site. Trained health personnel refers to at least one staff member trained to perform IUD insertions. About one-third (34.8\%) of the MSPAS centers met minimum availability requirements (having at least one IUD in stock, one insertion kit, one or more trained personnel, and adequate infrastructure), and 21.3 percent may be considered to have all elements necessary to offer the service.

\begin{tabular}{|c|c|c|}
\hline & Percent & $\mathrm{N}$ \\
\hline Centers who make service accessible & 72.1 & 43 \\
\hline Centers with limited schedule for IUD service (not accessible) & 27.9 & 43 \\
\hline \multicolumn{3}{|l|}{ Percentage of health centers that have: } \\
\hline Written IUD specific IEC material & 75.2 & 141 \\
\hline Visual IUD specific IEC material & 80.9 & 141 \\
\hline IUD information in health talks & 82.3 & 141 \\
\hline
\end{tabular}

Source: IUD Availability Survey - FRONTIERS Guatemala, 2002

Accessibility refers to centers that do not have limits on the number of days or the hours per day that they offer IUD services (i.e. that they offer the service upon request of the client). Written IEC material refers to the existence of at least one poster, pamphlet or flipchart on site. Visual IEC material refers to an IUD sample they can show to clients. Results shown in Table 4 indicate that 72.1 percent of clinics visited make IUD services available, 75.2 percent have written materials, 80.9 percent have visual IUD materials, and 82.9 percent provide IUD information in talks.

The great majority of surveyed clinics $(93.6 \%)$ have a private area in which to carry out gynecological examinations, although a slightly smaller percentage had a gynecological bed in this area $(90.8 \%)$. All surveyed clinics had electricity.

According to medical opinion, the basic and most essential equipment needed to safely carry out an IUD insertion consists of a speculum, a uterine sound, and a uterine clamp. Ninety percent of surveyed clinics had at least one adequate speculum in stock, while only 52.5 percent had a uterine sound. Seventy-eight percent had at least one adequate uterine clamp. Out of all surveyed centers, 47.5 percent have the basic IUD insertion equipment on site. In addition, 74.5 percent of clinics had scissors, 91.5 percent had disposable gloves, 77.3 percent had antiseptic solution, and 95 percent had an autoclave. Those clinics that had all these items in addition to the basic equipment were considered to have the full equipment necessary to offer IUD services. Thirty-five percent of surveyed clinics are considered to have full equipment.

Of the 49 units $(34.8 \%)$ that had the minimum conditions to offer IUD services, 69.4 percent offer the service effectively; this is to say that 30.6 percent do not offer the service despite the fact that they have the requirements to make the service available. Also, among the 30 centers $(21.3 \%)$ that 
have all the necessary conditions to offer the service, 83.3 percent effectively offer the service, although modestly, averaging less than five insertions per month.

Almost 54 percent of the surveyed centers have at least one IUD in stock, while 33 percent have more than five units. This means that 46.1 percent of clinics are out of IUD stock.

The great majority of surveyed health centers had at least one trained health worker able to provide IUD services ( $89.4 \%$ ). When analyzed by medical profession, 82.3 percent of clinics had at least one trained physician able to offer IUD services, while 47.5 percent of clinics had at least one trained nurse. Only 15.6 percent of centers had a trained nurse auxiliary able to offer IUD services.

The survey showed that although close to 90 percent of health centers have the necessary infrastructure and at least one trained worker in IUD insertion and removal, around half of them are still un-stocked and do not have adequate equipment (including a speculum, uterine sound, and uterine clamp) to offer the services. Efforts should be made to ensure that the proper equipment and adequate IUD stock are available to further expand the availability of IUD services as a contraceptive option for Guatemalan women.

\section{$\underline{\text { IGSS/APROFAM }}$}

Seven IGSS clinics and nine APROFAM clinics were surveyed to assess the availability of IUD services. Results of these surveys are presented in Table 5. This table shows that 57.1 percent of IGSS centers offered IUD services, although 85.7 percent had the necessary infrastructure and trained personnel, and 71.4 percent had the basic equipment required to offer the service. With respect to IUD supplies, 57.1 percent of the centers had one or more IUD in stock. These results point to the need for a better distribution of IUD supplies, given that those centers that had IUDs available were able to offer the services.

APROFAM centers showed much better conditions and more complete IUD services than IGSS clinics. Almost 89 percent of surveyed APROFAM clinics offered the service, and all had infrastructure, basic equipment, IUD supplies, and trained personnel available.

\begin{tabular}{|l|c|c|}
\hline \multicolumn{3}{|c|}{ Table 5. Availability of IUD services in IGSS and APROFAM centers } \\
\hline & IGSS & APROFAM \\
\hline & Percent $(\mathrm{N}=7)$ & Percent (N=9) \\
\hline Offer IUD services (1+) & 57.1 & 88.9 \\
\hline Infrastructure & 85.7 & 100 \\
\hline Basic equipment & 71.4 & 100 \\
\hline IUD supply & 57.1 & 100 \\
\hline Trained personnel & 85.7 & 100 \\
\hline
\end{tabular}

Source: IUD Availability Survey - FRONTIERS Guatemala, 2002 


\section{IUD service supply}

\section{$\underline{\text { Simulated Client Visits }}$}

Seventy-six simulated client visits were conducted in MSPAS health centers (30) and posts (45) in the Eastern and Western Highlands regions. Providers were visited by mystery clients of two profiles: a young woman wanting to space births and an older woman wanting to limit births.

Results from this study show that for young simulated clients wanting to space their births, 40.8 percent of providers offered at least one item of information about the IUD as a family planning method. About one-seventh (14.5\%) of providers offered only one item of information about the IUD, 15.8 percent offered two facts, and 10.5 percent offered three or more facts about this method. A total of 59.2 percent of providers did not mention IUDs to simulated birth-spacing clients.

When visited by an older mystery client wanting no more children, 28.9 percent of providers offered at least one item of information about the IUD as a long-term method. Only 6.6 percent offered one fact about the method, 3.9 percent offered two items of information, and 18.4 percent provided three or more facts and explanations. A total of 71.1 percent of providers did not offer any IUD information to simulated birth-limiting clients.

Table 6 shows the individual items of IUD specific information that providers should offer their clients. Results show that 26 percent of simulated clients, both wanting to space and limit births, were informed by their providers that the IUD is a small device made of plastic and copper. Slightly less than that, 22.4 percent of birth-spacing clients and 19.7 percent of birth-limiting clients were told that this device is placed inside the uterus. Close to 16 percent of providers informed both types of simulated clients that the IUD protects against pregnancy for up to 10 years. Close to 12 percent of birth-spacers and birth-limiters were informed that the device can be removed whenever the client wishes, 6.6 percent were informed that menstrual bleeding could increase, 2.6 percent were informed that menstrual pain could increase, and 1.3 percent were told that the IUD should not be used by women who have several sexual partners. It is noticeable that providers offered the same amount of IUD information to simulated clients regardless of the women's reproductive intentions.

\begin{tabular}{|c|c|c|}
\hline Percentage of women that received the following information: & $\begin{array}{c}\text { Birth- } \\
\text { spacers } \\
(\mathrm{N}=76)\end{array}$ & $\begin{array}{l}\text { Birth- } \\
\text { limiters } \\
(\mathrm{N}=76)\end{array}$ \\
\hline IUD is a device made of plastic and copper & 26.3 & 26.3 \\
\hline IUD is placed inside the uterus & 22.4 & 19.7 \\
\hline IUD protects against pregnancy for up to 10 years & 15.8 & 15.8 \\
\hline Woman can ask to have IUD removed & 11.8 & 11.8 \\
\hline Menstrual bleeding can increase & 6.6 & 6.6 \\
\hline Menstrual pain can increase & 2.6 & 2.6 \\
\hline IUD can not be used by women with several partners & 1.3 & 1.3 \\
\hline
\end{tabular}

Source: MSPAS Family Planning Care Study - FRONTIERS Guatemala, 2001 
This study also analyzed the proportion of information items mentioned during family planning care for each contraceptive method, with respect to the total number of items that should be mentioned according to national norms. Results show that providers, on average, are offering only 12 percent of all the information that women should be given in order to make an informed choice regarding IUDs. On average clients received 36 percent of the information for Depo-Provera, 36 percent of the information regarding oral contraception, and 25 percent of the information for condoms. Using a paired-sample t-test, simulated spacing clients received significantly less information about IUDs than they did about Depo-Provera ( $\mathrm{t}$-test $=-8.293$, $\mathrm{p}$-value $<0.001$ ), oral contraceptives ( $\mathrm{t}$-test $=-9.138$, $\mathrm{p}$-value $<0.001)$, and condoms $(\mathrm{t}$-test $=-4.183$, $\mathrm{p}$-value $<0.001)$.

Results among simulated clients seeking to limit births are similar. Clients received 12 percent of all IUD information that should have been offered, 39 percent of Depo-Provera information, 28 percent of female sterilization information, and 14 percent of male sterilization information. Providers offered significantly less information about the IUD than they did about Depo-Provera ( $t$ test $=-8.564, \mathrm{p}$-value $<0.001$ ) and female sterilization ( $\mathrm{t}$-test $=-4.636, \mathrm{p}$-value $<0.001)$. The difference between IUD and male sterilization was not significant.

The study results indicate that providers offer less information about IUDs in relation to other methods, both for women that seek to space births and for those that seek to limit them. This result is important because women with very different profiles, and thus different reproductive needs, are given essentially the same contraceptive information and therefore the same contraceptive options regardless of their reproductive intentions. A majority of family planning providers did not mention the IUD to their clients at all, indicating that it is largely not offered as a contraceptive option for women seeking to space or limit births.

\section{$\underline{\text { Service Provider Interviews }}$}

In order to assess service provider knowledge and acceptability towards IUDs, a study using semistructured interviews was conducted with providers of 42 MSPAS centers, 16 IGSS clinics and hospitals, 20 APROFAM clinics, and nine NGO clinics of the Central, Eastern and Western Highland regions of the country. The visited health centers were approximately equally distributed among the three geographic regions, with the exception of the NGO clinics, which were all in the Eastern and Western Highland regions. Table 7 describes the study sample by service provision institution and geographic location.

\begin{tabular}{|l|c|c|c|c|}
\hline Table 7. Description of the sample & Central & $\begin{array}{c}\text { Western } \\
\text { Highland }\end{array}$ & Eastern & Total \\
\hline MSPAS & 16 & 13 & 13 & 42 \\
\hline IGSS & 6 & 5 & 5 & 16 \\
\hline APROFAM & 6 & 6 & 8 & 20 \\
\hline NGO & -- & 7 & 2 & 9 \\
\hline Total & 28 & 31 & 28 & 87 \\
\hline
\end{tabular}

Source: Service Provider Interview Study - FRONTIERS Guatemala, 2002 
Ninety-five percent of interviewed health care professionals provide family planning counseling in their health centers and clinics. Of those that offer this service, 85.5 percent include the IUD among the methods they discuss with potential clients. The most commonly cited reason for not talking about IUDs was that the center did not have the method available or they did not have a trained professional onsite to insert and remove IUDs. One physician explained:

“... because I can't offer the service if they [physicians] don't insert them. I think they [clients] would not be inclined to choose a method that we don't have available here in the center."

The quality of IUD family planning care was evaluated by constructing a scale with 11 items of information that should be given to clients to allow an informed choice. Results show that MSPAS health providers mentioned an average of 2.8 items of information during counseling, IGSS providers mentioned 3.6 items, APROFAM providers mentioned 4.7 items, and NGO providers mentioned 4.2 items of information related to IUDs. A statistically significant difference was found in the mean number of items mentioned, with APROFAM providers mentioning on average two items more than MSPAS providers, and around one item more than IGSS providers $(\mathrm{t}$-test $=6.048$, $\mathrm{p}$-value $=0.004)$.

\section{Acceptability of IUDs as a contraceptive choice}

\section{Knowledge, attitudes, and opinions about IUDs among Guatemalan women: a qualitative appraisal}

Thirty focus groups were carried out with current family planning users of re-supply methods, sterilized women, and past or current IUD users in the Central, Eastern, and Western Highland regions of the country. The results of this study show that from the demand side, the reasons for low IUD use among family planning clients are numerous. These have been classified according to the following topics: knowledge about the method, accessibility, attitudes, disadvantages, and quality of services.

\section{$\underline{\text { Knowledge }}$}

In all three geographic regions of the country, women lack information and are misinformed about the IUD, regardless of their current family planning situation. The lack of knowledge regarding this method is especially accentuated among non-IUD users. In some communities, the IUD was completely unknown to FGD participants, while in other communities from the Western Highland region even the name of the method was unknown to the participants. In all three regions, participating women had insufficient knowledge about IUDs. Some participants were familiar with the name, shape, and where it is placed in the body, but were not familiar with the way it functions, its indications and contraindications. Many other women had misconceptions regarding the physical shape of the device, its placement, the way it functions, indications and contraindications. The women commented:

\section{"I only know that I think it goes knotted around the fallopian tubes."}


"I think it works because it covers up, they say that the uterus has a little hole, I think they place it through the hole, and that's why you don't get pregnant."

\section{Accessibility}

Several problems were identified related to accessibility. Despite the fact that IUD services are offered in some public and most private health services, in all three regions there were women who did not realize that this method was available in MSPAS centers or IGSS clinics. Similarly, women generally did not know the cost of an IUD, or believed the price was much higher than the APROFAM price used as reference (Q69 or US\$9 for an IUD, including insertion appointment). Even though comparatively speaking, the price for an IUD insertion, including follow-up visits (with Pap smear), for a year is less expensive than the cost for other methods such as condoms or injections, IUD services require a single payment and thus constitute a financial barrier for many women. Many participants believed that the comparatively higher price of IUDs constituted an accessibility barrier. Most women thought that having to pay between Q60 and Q150 (about US\$8 -- \$20) for the service would limit the number of women from their communities that could access the service. One woman reported:

"Some women may be able to pay that price, but others can't. That's why we come to the health center, because we know it's free here."

Furthermore, given that this service is mostly offered in hospitals and clinics in urban areas, women living in rural or urban communities with limited access to health services must consider transportation costs in addition to the IUD service costs. Similarly, women from all three regions reported that they could not have immediate access to the service due to institutional regulations. These included arriving for insertion while menstruating, having a pregnancy test done prior to insertion, being interviewed by a provider, conforming to a specific schedule or requesting an appointment, and presenting children's immunization card.

\section{$\underline{\text { Attitudes }}$}

In all three regions, and with all three groups of women in the FGDs, many fears toward IUDs were reported. These fears were classified as follows: facts, side effects, and rumors. Among the facts, there was more concern about method failure than there was about pain during insertion. Fears about method failure were more common among IUD users, particularly those who were unfamiliar with the effectiveness of the method. Pain during insertion did not come up as a fear or concern in FGDs in the Western Highland region. Side effects such as having more abundant menstrual bleeding and increased menstrual cramps were a commonly expressed fear among women of all three regions. For example, one IUD user said:

"They told me it was very painful when it's placed. It wasn't until I talked to Doña Julia, she told me it didn't hurt. That's why I decided to put it in, but people scare you." 
Part of the fears expressed by women can be classified as rumors, which represent a barrier for the acceptance and integration of the IUD in the communities. Women referred to 15 rumors, of which six were classified as rumors about long-term effects, and three as rumors about effects on the unborn child. Of the 15 rumors, the most important ones (reported in most groups in all regions) were: the IUD can get stuck on the unborn child's head, face or body; it causes cancer; it becomes embedded within the tissue of the uterus; it can cause an abortion, and it is uncomfortable during sexual intercourse. Some FGD participants observed:

"Because [the IUD] becomes embedded, people say that they've had to have an operation to get it out."

"I heard on a radio station, I can't remember which one, that they said...the seed comes, then the copper T dissolves it and it comes out in menstruation. So, I heard that the copper T wasn't recommended because it causes abortion. I heard it on the radio."

The less common rumors (reported by one of four groups) include: the IUD gets lost within the body, it sterilizes women, it moves or is expulsed when performing rigorous exercise, it provokes weight loss or weight gain, it provokes chronic pains, it causes infections or serious illnesses. Participants commented:

"[I heard that] it falls inside and then it goes towards the ribs."

"I have the experience with one of my neighbors. She had her first baby and didn't take care of herself. Three months later she was pregnant again. The second baby came and she thought she was going to get pregnant again, so she used the copper T and she couldn't have any more babies. She stayed with only two children and they said it was because of the T."

Women not only reported rumors they heard within their communities, but also reported those rumors that, to them, hold the "truth." In order of importance, these are: that IUDs cause cancer, they get embedded, they get lost inside the body, and they get stuck to the unborn child and cause abortion. For those women who perceive these rumors as true, pain during insertion (fact), heavier and more painful menstruation (side effect), and the onset of cancer (rumor) all belong to the same symbolic universe that influences their family planning behavior.

\section{Disadvantages and advantages}

The disadvantages of the IUD compared with other family planning methods partially explain why women do not choose this method over others. FGD participants reported nine disadvantages, which were classified as: financial, physiological, practical, social, and generic. The most important disadvantages from the user's point of view are: increased menstrual flow, risk of pregnancy due to method failure, pain involved in the process, and the increased risk of infections. Examples of their perceptions include:

"Some people have it placed and still become pregnant." 
"I have a sister-in-law that had it, but she used to have a lot of infections, and she had pain where she had [the IUD] so she had to have it removed."

Other disadvantages reported include: the time required for follow-up visits, embarrassment during the gynecological exam, lack of confidence in male physicians' medical attention, periodic monitoring and IUD removal, the relatively high price due to single payment, the pain experienced during the insertion and removal, the male sex of health care providers, and the jealousy of each woman's husband.

"For me the disadvantage is that I had to go very often to the gynecologist and he had to be touching my vagina."

The advantages of the method mentioned by participants can be summarized in three categories: financial, physiological, and practical advantages. In all three geographic regions women mentioned that the price of the IUD service is comparatively cheaper than other methods. Among sterilized women, participants agreed that the price of the IUD service was lower than female sterilization. One woman observed:

"It's an expense [that covers] a long period of time. Not like with other methods.

With injections its every three months, with pills it's every month."

Physiological advantages included that IUDs do not produce weight gain, alter the nervous system, or cause headaches. Women in all three regions also indicated that it was an advantage that IUDs do not cause amenorrhea. This point is important, given the cultural belief that the menstrual period is a monthly purification process that affects the body if absent. One woman commented:

"Menstruation is the outlet of the body. If it doesn't come out the woman gets fat."

Practical advantages included the length of protection, the fact that it does not require daily actions by users and that it is a reversible method that can be used over a long period of time. The women commented:

"When you have [the IUD] placed you don't have to move it or mess with it. You don't forget, like the pill, because it's already there and there's no need to be remembering every day to take something."

"With the copper T, if you want a child you can have it removed. In the case of all of us that are operated on, I've been told that I had it done too young and I'm going to want a baby later on...I don't think so." 


\section{Quality of services}

Several problems were identified related to the quality of health services that possibly contribute to the lack of demand for IUD services, the lack of satisfaction with the method, and the discontinuation rate. Although some women report that health centers and clinics offer several family planning methods, other women, particularly from the Eastern and Western Highland regions, report that there are still some centers that give preference to one method (such as DepoProvera) over others (such as the IUD). The inclusion of IUDs in the supply of methods is still not consistent throughout the country. Women that use other contraceptive methods report not being exposed to this method, especially in the Eastern and Western Highland regions. Some IUD users from the Central and Western Highland regions reported that they were not given information about the IUDs; it was simply offered to them and inserted in their uterus. One user said:

"They only showed it to me when they took it out. When they inserted it I was left in doubt. Until I went to have it removed, I didn't see it."

Another factor that affects the demand for IUDs is that family planning consultations still do not consistently include visual materials that explain the method in detail. Generally speaking, women who have made a decision to use family planning have done so with or without the husband or partner's participation. But in the Central region, some women reported that the decision about the family planning method was primarily made by the provider:

"I wanted to have the injection every three months. But the doctor said no, because why did I want to bring more children into this world? 'Why do you want to have more babies? You can't have any more children; with four already you took a big risk. So, it's definitive that you have to get an operation. “

"I decided to use the copper $T$ when my son was born and I was sick with nervousness. So the doctor said that using pills and injections were going to alter my nerves, so he decided - as I told you at that time the T was really popular - so he recommended the copper $T$. And since he was a very strict and direct doctor, there was no chance to ask questions. Then he said, 'I recommend the copper T, or do you want to be sick again?' So I was scared to get sick again...So we decided for the T."

Information about side effects and periodic check-ups is still not consistently included in the family planning services offered to IUD users, especially in the Eastern and Western Highland regions.

\section{Acceptance}

Among sterilized women who had previously been IUD users, most would not recommend the IUD as a contraceptive method to other women due to their lack of satisfaction with the method, mostly due to method failure and side effects. Among sterilized women that had not previously been IUD users, some women said they would not recommend the method either due to their lack of knowledge about it and for fear that they would be held responsible in case the method caused any unwanted effects. One woman said:

Availability and Acceptability of IUDs in Guatemala 
"I couldn't recommend it because I'm not familiar with it; I never used it."

However, some sterilized women realized that the IUD could have been an option for them as a reversible, yet still long-term, method. Women from several focus groups said they regretted being sterilized due to changes in their circumstances.

"Because my daughter now is five years old. She's going to start school now, and I'm going to stay behind. Sometimes I feel it would be nice to have another baby, and I'm so young, too."

Among women using other temporary methods, differing opinions were expressed when asked if they would consider using IUDs in the future. Those women who had a favorable attitude towards IUDs and would consider them in the future based their answers on the advantages of the method. Some women from the Central region said they would recommend the method to other women due to its longer duration and the absence of amenorrhea. Despite this, the practice in all three regions was to not recommend IUDs. Those women who said they did not consider using the IUD in the future based their answers on fears and rumors, as well as wrongful information about the method. One commented:

"I would like to use the copper T, but because of what they say that it becomes embedded and all that, sometimes I'm scared."

Among women who are ex- or current IUD users, the method was generally accepted, and women expressed great satisfaction with it. Its continued use is essentially based on the advantages such as its low failure rate and the lack of problems with side effects. A current user reported:

"I started using family planning when my girl was two months old. Before it was too late, I decided to have [an IUD] inserted. And to date, thank goodness, I haven't had any problems. I've had it for 10 years, and it's been seven years since my last check-up."

The primary reasons ex-IUD users had for stopping IUD use was a planned pregnancy, which speaks favorably about the ability for reproductive planning offered by this method. Although some current and past users would not recommend the method to other women, most users would and do recommend it. Their positive attitudes towards the method are based on its effectiveness, positive personal experiences, the lower price of the method relative to other methods, the advantage of not needing a daily action, and the reversibility of the method compared to sterilization.

\section{Do service providers accept IUDs?}

As mentioned in the previous section, 87 semi-structured interviews with service providers were conducted in the Central, Eastern, and Western Highlands regions of the country. Providers were drawn from MSPAS health centers, IGSS, APROFAM, and NGO clinics in 16 health areas within these regions. 
Results show that more than half (52.9\%) of interviewed providers had ever been trained in IUD insertion and removal. During training, almost 30 percent had practiced inserting an IUD under supervision with actual clients, and 24.1 percent had practiced removing an IUD with clients. The mean number of days used to train for insertions and removals was 2.1.

Among those providers who had undergone training, 34.8 percent had done so within the last year. Thirteen percent were trained approximately two years ago, 4.4 percent were trained three years ago, 6.5 percent were trained four years ago, and 41.3 percent were trained five or more years ago. There was no significant difference in the number of years since the previous training for the providers between institutions.

With respect to knowledge about IUDs, providers were asked to name related side effects and contraindications. This study determined the number and proportion of correct and incorrect answers per respondent. Twenty-five percent of providers did not know any IUD-related side effects, 36 percent mentioned only one side effect, while 39 percent could report the two most common side effects related to IUD use. The majority $(72.4 \%)$ of interviewed providers spontaneously mentioned heavy menstruation as a side effect, and less than half (44.8\%) mentioned increased menstrual pain as a side effect.

Thirteen percent of providers did not know any IUD-related contraindications. The majority (72\%) of providers interviewed could mention between one and three contraindications, and 15 percent could mention between four and six contraindications for the method. The mean number of contraindications mentioned was above two (2.3). This indicates a relatively low level of knowledge about which women should not be advised to use this method.

While analyzing the data, any side effects or contraindications mentioned by providers that were not medically correct were recorded as misinformation about the method. More than half (54\%) of the interviewed providers were misinformed about the side effects caused by IUDs. With regards to contraindications, 28.7 percent of providers were misinformed about when women should be advised against the method.

Providers were also asked to mention the fears that clients reported most concerning IUDs, and then respond to whether they thought those fears were medically founded. Among reported fears that providers shared with their clients, 14 percent of providers believed that the IUD method failure rate was a concern, 6.9 percent thought that the IUD caused discomfort during intercourse, 5.7 percent believed that in case of a pregnancy the IUD could have side effects on the fetus, 3.4 percent believed IUDs cause abortions, and 3.4 percent believed the IUD can become embedded in the uterus.

Fifty-five percent of providers believed the demand for IUD services had decreased or remained the same since they had started to work in their particular clinic or center, while 44 percent thought demand for the service had increased. Providers were then asked whether they thought IUDs were highly used or rarely used among the community served by the clinic. Ninety-three percent thought IUDs were rarely used. Once again providers were asked to give their opinion about why 
they thought IUD use was high or low. Close to 46 percent of them thought that IUD use was low due to women's attitude about the method, 36.1 percent responded that provider's attitudes explained the low use of the method, 12 percent thought that the popularity of Depo-Provera explained the low use of IUDs, and 6 percent thought that the characteristics of IUDs explained the low use.

According to providers, the most frequently mentioned attitudes that women had which contribute to keeping IUD use low were: fears and rumors about the method, mistrust towards the providers, and preference for other methods. The most commonly reported provider attitudes contributing to low IUD use were: lack of method promotion, lack of interest, provider preference towards other methods, and lack of trained personnel or supply.

\section{CONCLUSIONS}

The method mix for the three most important family planning service systems in Guatemala (MSPAS, IGSS, and APROFAM) is primarily dominated by female sterilization and DepoProvera. IUD use is very low, suggesting that there is a bias against the method, particularly in MSPAS health centers. In the case of MSPAS, only five health areas insert, on average, more than 10 IUDs per month, and 11 health areas have a monthly average of less than five IUD insertions. IGSS statistics show that around 90 percent of all IUD insertions are done in hospitals and clinics in Guatemala City, indicating that the institutional capacity of IGSS clinics is largely wasted outside Guatemala's metropolitan area.

There are several supply factors that limit the availability and acceptability of IUD services throughout the country. Despite the fact that the institutional capacity to offer this service already exists in over one-third of MSPAS centers, over half of IGSS clinics, and in all APROFAM clinics surveyed, not all the centers that have the capacity to offer this service are currently doing so. The study found two important factors that predict whether an MSPAS health center offers IUD services: having at least one IUD in stock and at least two practitioners trained in IUD insertion and removal.

The negative attitudes of family planning care providers with regard to IUD services are a second supply-side factor. Despite the fact that the majority of providers have been trained in IUD insertion and removal, many are still misinformed regarding the IUD, specifically concerning side effects and contraindications for the method. More than half of the service providers interviewed for this study had incorrect information about what side effects were produced by IUDs, while slightly less than one-third had misconceptions of when the IUD was contraindicated. Providers also treat women similarly regardless of their reproductive intentions, as seen through the experience of simulated clients. Focus group discussions also revealed that women seeking longterm methods are rarely offered the IUD as an alternative to sterilization. Providers also cite demand factors for the low use of IUDs. Nevertheless around one-third of providers do recognize that supply factors contribute to the generally low use of this method, mostly blaming the lack of information and institutional capacity. 
Thirdly, almost half of the MSPAS health centers surveyed during the study had no stock of IUDs, although the health areas reportedly stock all centers on a monthly basis. This fact suggests logistical problems in the distribution of family planning methods from health areas to health centers and posts.

Drawing primarily from focus group discussion results, on the demand side women want to receive more information about IUDs. They do not perceive the method to be available to them, and many women suggested that the service be brought to them in their communities instead of having to go to health centers in urban areas to access IUD services. Women still are misinformed about the method and have many fears on the side effects it may produce. Myths are strongly held and spread as rumors, keeping many women from asking providers for more information. Some of these rumors are that IUDs have a high failure rate, they become embedded in the uterus, they cause side effects for the fetus, and they cause cancer. Many women would rather go to a service offered by female doctors, partly due to mistrust of male doctors, as well as reluctance to undergo a gynecological examination. Nevertheless, among those women that are currently using or have used an IUD in the past, most of them are satisfied with the method and base their satisfaction of the advantages it has compared to other temporary methods.

Although IUDs have not constituted a popular contraceptive method among family planning users in Guatemala, women need more information from their health care providers in order to make informed choices about their family planning preferences.

\section{RECOMMENDATIONS}

Programmatic recommendations derived from this study are separated into those concerning the supply and those concerning the demand. Recommendations for the supply side are as follows:

- $\quad$ Further training for health care providers must be tailored to include more detailed information about side effects and contraindications. Specifically, provider training should include strategies on how to handle clients' fears and common myths during family planning counseling. Training programs should also emphasize that providers must take into consideration women's reproductive intentions during family planning care in order to achieve a better match between women's needs and their method of choice.

- Teams of health care workers should be trained to offer the service, not just individuals within health centers and clinics, given that the probability of offering IUD services increases when at least two health workers are trained in each center.

- Measures should be taken to use resources more efficiently, given that many centers and clinics have the technical capacity to offer IUD services and are not taking advantage of it. In order to more efficiently use the technical capacity established we recommend the following:

Implementing campaigns to consistently provide information about family planning services, including IUD services. 
Transferring IUD insertion and removal equipment from sites that are not using it to facilities where it is more likely to be used. This may involve transferring equipment to the primary level of services.

$>$ Training paramedic personnel to offer IUD insertion and removal services.

$>$ Training and equipping mobile doctors in order to extend the family planning coverage, including IUD services.

- Ensure that family planning methods, including IUDs, are efficiently distributed to health centers and posts, avoiding undue delays at these sites.

- Specifically for IGSS, we recommend expanding IUD services to clinics outside Guatemala City.

- Specifically for APROFAM, we recommend training and strengthening their mobile units in order to bring family planning services, including IUD services, to rural areas. Similarly, encouraging rural promoters to refer women to clinics if they choose to use an IUD.

Recommendations referring to the demand side of IUD services include:

- Including more detailed information about common myths and fears regarding the IUD during family planning counseling.

- Including personal accounts of satisfied IUD users in informational material in order to make women aware of the advantages of this method over others.

- Emphasize that IUD services can also be offered by female practitioners, including physicians, nurses, and some nurse auxiliaries. Providers should let their clients know that IUDs would only be inserted if all conditions are fulfilled (i.e. a private space and all technical requirements).

\section{DISSEMINATION AND UTILIZATION}

Results of this study were presented in August 2002 to key actors in the reproductive health field in Guatemala including USAID, the Calidad en Salud program, and MSPAS, IGSS, and APROFAM representatives. The availability information has been used by Calidad en Salud to evaluate progress made in providing equipment, training and supplies to MSPAS health centers and posts. IGSS and APROFAM were able to identify clinics where use of available resources may be improved. The Inter-agency Working Group on IEC has requested a detailed report of focus groups to help design a radio-based campaign that is under development.

In addition to providing information to key stakeholders in the family planning field in Guatemala, this project has provided the basis to guide the Calidad-led initiative to make IUD services available to rural populations in Guatemala. Calidad en Salud and FRONTIERS have started a collaborative project to train nurse auxiliaries to insert IUDs and provide more balanced 
contraceptive options to rural women. This activity complements the current IEC activities led by Calidad en Salud.

\section{REFERENCES}

León, F. R., M. E. Costa, P. Jácome, J. Ordóñez, E. Ottolenghi, M. Espinoza, \& R. Monge (1998) "Developing algorithmic instruments to help providers and users to implement the new Reproductive Health Care Guidelines issued by the Ministry of Public Health of Ecuador." Final Report of INOPAL III Sub-Project. Lima: Population Council.

León, F. R. (2000) "Provider and client impacts of an interaction designed to improve the providerclient interaction in Ministry of Health clinics in Peru." FRONTIERS operations research proposal. Lima: Population Council. 